https://doi.org/10.36105/iut.2020n31.08

\title{
EJERCICIO DE COMPETENCIA DISCRECIONAL DEL REGISTRO PÚBLICO DEL DERECHO DE AUTOR EN EL PROCEDIMIENTO DE INSCRIPCIÓN DE OBRAS LITERARIAS Y ARTÍSTICAS
}

\begin{abstract}
EXERCISE OF DISCRETIONAL JURISDICTION OF THE PUBLIC REGISTRY OF COPYRIGHT IN THE PROCEDURE OF REGISTRATION OF LITERARY AND ARTISTIC WORKS
\end{abstract}

\author{
CARlos Hernández LóPez* \\ Investigador independiente, México \\ carlhez@hotmail.com
}

\section{RESUMEN:}

La Ley Federal del Derecho de Autor prevé los supuestos mínimos de protección para los autores y sus obras, y dispone que dichas creaciones pueden ser inscritas en el Registro Público del Derecho de Autor del Instituto Nacional del Derecho de Autor. A este respecto la autoridad administrativa en materia de derechos de autor realiza el registro o niega la inscripción de las creaciones que se le presentan en ejercicio de una competencia discrecional, en virtud que, si bien tiene competencia y atribuciones para hacerlo la legislación no prevé bajo que conceptos y características una creación corresponde a una de las ramas reconocidas por el derecho de autor de las que se enuncian en el artículo 13 de la Ley Federal del Derecho de Autor, el perfil que debe tener quien realiza la evaluación de las obras literarias y artísticas para determinar la procedencia o improcedencia de la inscripción y el procedimiento de dictamen de las creaciones intelectuales.

\footnotetext{
* Licenciado en Derecho por la Universidad Nacional Autónoma de México, Maestro en Administración por la Escuela Bancaria y Comercial y candidato a Doctor en Administración Pública por la Universidad Anáhuac México. Entre las actividades desempeñadas en su trayectoria laboral se encuentran los cargos que ocupó en el Instituto Nacional del Derecho de Autor como Jefe de Departamento de Inscripción de Obras, Jefe de Departamento de Inscripción de Contratos, Subdirector de Reservas, Subdirector de Registro de Sociedades de Gestión Colectiva y Anotaciones Marginales, Subdirector de Procesos y Director de Arbitraje.
} 


\section{Palabras clave:}

Administración Pública; Competencia Discrecional; Derechos de Autor; Creación Intelectual; Registro de Derechos de Autor.

\section{ABSTRACT:}

The Federal Copyright Law provides the minimum protection assumptions for authors and their works, and provides that such creations can be registered in the Public Registry of Copyright of the National Institute of Copyright. In this regard, the administrative authority in copyright matters registers or denies the registration of the creations that are presented to it in the exercise of discretionary competence, by virtue of the fact that, although it has competence and powers to do so, the legislation does not provide under what concepts and characteristics a creation corresponds to one of the branches recognized by copyright of those set forth in article 13 of the Federal Copyright Law, the profile that the person carrying out the evaluation of literary works must have and artistic to determine the origin or inadmissibility of the inscription and the procedure of opinion of the intellectual creations.

\section{Keywords:}

Public Administration; Discretionary Competition; Copyright; Intellectual Creation; Copyright Registry.

SUMARIO: I. Nota introductoria. II. Ejercicio de competencia discrecional del Registro Público del Derecho de Autor en el procedimiento de inscripción de obras literarias y artísticas. III. Bibliografía.

\section{NOTA INTRODUCTORIA}

La investigación y sus resultados a los que se hará referencia en el presente documento tienen su origen en acontecimientos de hace aproximadamente veinte años y que permanecieron archivados en la memoria hasta hace casi un par de años atrás que se trajeron a la actualidad, podría decir, por un hecho muy casual.

Hace dos décadas al iniciar labores en la Administración Pública Federal en el Instituto Nacional del Derecho de Autor, un Órgano Desconcentrado en aquel momento de la Secretaría de Educación Pública (ahora de la Secretaría de Cultura), tuve dos encomiendas principales en el Procedimiento de Registro de Obras literarias y artísticas. Una de ellas era la recepción de solicitudes conforme a un nuevo propósito que en aquel momento consistía en que la atención al público usuario fuera realizada por profesionistas con perfiles de abogados, la otra actividad era el dictamen de las solicitudes y las obras para elaborar los proyectos de registro y de negativas de inscripción.

En estas dos actividades la supervisión la realizaba la Subdirección de Registro de Obras y Contratos de la Dirección del Registro Público del Derecho de Autor, Área encargada principalmente de la emisión de las resoluciones en el 
Procedimiento Administrativo de Registro de Obra, y que en aquella época — como puede decirse que sucede también en la actualidad - el resultado de los dictámenes por lo que respecta a la evaluación de las creaciones intelectuales presentadas para su registro para determinar si se trataba de una de las creaciones protegidas por el Derecho de Autor conforme al listado de las ramas reconocidas por el Derecho de Autor dispuesto por el artículo 13 de la Ley Federal del Derecho de Autor, dependía de la concepción que el funcionario facultado tenía de cada una de las ramas de obras literarias y artísticas, salvo algunos casos en los que dicho ordenamiento legal provee de sus definiciones, en concreto, la rama de programa de cómputo, obra audiovisual y de compilación de datos.

Es así, que hace no más de dos años se tuvo la oportunidad de ver el resultado de un trámite para la inscripción de una creación intelectual, conforme al Procedimiento Administrativo de Registro de Obra en el que, distinto a la petición realizada mediante la Solicitud de Registro de Obra, se emitía un certificado de registro en una rama distinta, que originó la investigación, análisis y disertación del tema.

\section{EJERCICIO DE COMPETENCIA DISCRECIONAL DEL REGISTRO PÚBLICO DEL DERECHO DE AUTOR EN EL PROCEDIMIENTO DE INSCRIPCIÓN DE OBRAS LITERARIAS Y ARTÍSTICAS}

La investigación a la que se hace referencia se intituló: Ejercicio de Competencia Discrecional del Registro Público del Derecho de Autor en el Procedimiento de Inscripción de Obras Literarias y Artísticas, y fue realizada como tesis para obtener el grado de Doctor en Administración Pública con la hipótesis de que la falta de un procedimiento de registro de obras literarias y artísticas con ausencia de ejercicio de competencia discrecional se explica por el dictamen deficiente de las creaciones intelectuales, por la carencia de definiciones legales de las ramas sujetas de protección y la necesidad de expertos en la evaluación de las creaciones intelectuales.

Así, se planteó como problema para brindar certeza y seguridad jurídica la existencia de ejercicio de competencia discrecional en el procedimiento administrativo de inscripción de obra en el Registro Público del Derecho de Autor del Instituto Nacional del Derecho de Autor (INDAUTOR), en virtud que, la Ley Federal del Derecho de Autor concede competencia al Órgano administrativo, el Reglamento Interior del INDAUTOR otorga atribuciones al Director, los Subdirectores y al Jefe de Departamento, todos ellos del Registro Público del Derecho de Autor, aunque no se cuenta con conceptos de la mayoría de las ramas reconocidas por el derecho de autor, ni un perfil que defina las aptitudes necesarias para las personas que deben realizar la evaluación de las obras literarias y artísticas, así tampoco, un procedimiento de dictamen de las obras.

La investigación involucra la gestión del trámite de Solicitud de Registro de Obra mediante el cual los servidores públicos con atribuciones para su gestión fundados en la Ley Federal del Derecho de Autor determinan la procedencia de 
la inscripción de las creaciones intelectuales que se presentan para su inscripción en el Registro Público del Derecho de Autor del Instituto Nacional del Derecho de Autor, órgano competente para esos efectos, basados en su mayoría ${ }^{1}$ en conceptos, criterios o consideraciones de su elección para emitir sus resoluciones a falta de definiciones legales de la mayoría de las ramas reconocidas por el Derecho de Autor.

Así también, las actividades que realiza la autoridad registral para la atención de las Solicitudes de Registro de Obra se ciñen a un procedimiento que carece de la descripción normada de las etapas que se llevan a cabo para el dictamen o evaluación de las creaciones intelectuales y las capacidades, aptitudes o el perfil requeridos en la persona que lleva a cabo dicho dictamen vinculadas al conocimiento de las creaciones artísticas.

La Administración Pública, como lo señala Ávalos, se organiza a través de un cúmulo de normas jurídicas que disponen la competencia de las entidades y órganos a quienes corresponde el ejercicio de la función administrativa mediante atribuciones y competencias asignadas a través de los servidores públicos conforme la responsabilidad que les corresponde acorde con sus funciones, capacidad y aptitud para la labor encomendada. ${ }^{2}$

Con referencia a la facultad discrecional, Madariaga señala que se caracteriza por otorgar a la autoridad administrativa una potestad jurídica sujeta de control para poder elegir con el objetivo de vincular dicha selección con la competencia otorgada por la norma por parte de los órganos administrativos. ${ }^{3}$

Es cierto que hay casos en los que la autoridad en el ejercicio de su competencia actúa con discrecionalidad en virtud que la ley no precisa los mecanismos a los que debe sujetarse ni los criterios o conceptos que sirven como parámetros para distinguir términos que no se encuentran definidos por la norma como es el caso del Registro Público del Derecho de Autor del Instituto Nacional del Derecho de Autor.

Así, la actividad del Estado puede distinguirse en dos sentidos una reglada que surge ante la existencia de normas que determinan su forma de actuación y precisan cierta decisión en favor del ciudadano y, por otro lado, una actividad discrecional que se deriva de un margen de apreciación señalado por la norma en el que el funcionario puede elegir entre varias alternativas de solución. ${ }^{4}$

De acuerdo con Borges y Gayoso, por potestad reglada se entiende como la que se encuentra debidamente regulada por el ordenamiento jurídico y, por ello, es la propia norma la que designa la autoridad que debe actuar, cuándo debe hacerlo y el procedimiento para ello. En otro sentido, la facultad discrecional permite a la

1 Se precisa que, al decir: en su mayoría, se refiere a que solo en algunos casos, el legislador previó un concepto en la Ley Federal del Derecho de Autor respecto de las ramas reconocidas por el derecho de autor, como son la rama de programa de cómputo, la rama audiovisual y compilación de datos.

2 ÁVALOS, Eduardo et al., Derecho administrativo 1, España: Alveroni Ediciones, 2014, p. 76.

3 RÍOS, Lautaro, Los poderes discrecionales, citada de su obra Derecho administrativo y seguridad jurídica, en Revista de Administración Pública, núm. 099. España: Centro de Estudios Políticos y Constitucionales (CEPC), 1982, p. 405.

4 ÁVALOS, Eduardo, et al., 2014, pp. 16 y 17. 
autoridad cierta libertad de apreciación en el ejercicio de sus potestades mediante la valoración subjetiva de asuntos concretos sin tratarse del ejercicio del poder por encima de la ley, sino que se forma a partir de ella y busca seleccionar la mejor opción en beneficio de la propia administración. ${ }^{5}$

En la facultad discrecional existe un margen de actuación basado en una valoración subjetiva, de tal forma que, el resultado dependerá de la evaluación conforme al criterio que decida ocupar la Administración Pública, por lo que, con excepción de que exista una norma expresa para el caso, puede decirse que en el ejercicio de la potestad discrecional existe cierta tolerancia concedida por el legislador mediante la cual la autoridad concede determinados privilegios según su criterio a la hora de resolver y que terminan siendo lícitos y tienen el objetivo de que se satisfaga el fin que persigue la Administración Pública en favor de sus gobernados. ${ }^{6}$

Se dice que no hay actos que no se encuentren reglados, sino que se encuentran en mayor o menor grado regulados por una disposición jurídica en virtud del margen de actuación o apreciación que le sea atribuido por el legislador a la autoridad para elegir entre diversas opciones. ${ }^{7}$

Con referencia a la facultad o potestad discrecional dice Rizo que su poder de apreciación se ha transformado de ser una aptitud de dominación en favor de la autoridad administrativa a un mecanismo que utiliza ésta para adecuar los escenarios que se le presentan con el objetivo de cumplir el fin que le corresponde al órgano que representa y conocer en qué momento actuar, cómo debe hacerlo y de elegir el contenido que va a dar a su actuación, además de que conforme las disposiciones jurídicas que la rigen le suelen otorgar las libertades para decidir si debe hacer o abstenerse. ${ }^{8}$

El control de la discrecionalidad administrativa es un tema complejo no hay que dejar de lado que se produce en la norma que es donde se autoriza a la Administración Pública el ejercicio de una potestad mediante la cual se le provee de un margen amplio de apreciación bajo estándares de tolerancia ante varias opciones legales de solución a su elección. En virtud de ello, en las potestades discrecionales no todos los elementos se encuentran reglados ya que algunos de los que se mencionan a continuación no lo están: ${ }^{9}$

- Competencia: se trata de un órgano facultado para ejercer la potestad.

- Debe haber un procedimiento de aplicación: se trata de la serie de pasos o actividades previstas en el ordenamiento para resolver un asunto.

- Motivo o fin: se tiene fin específico por el que se originó la potestad.

5 BORGES, Jorge Luis y ARIAS, Grethel, Discrecionalidad y legalidad. Cuba: El Cid Editor | apuntes, 2009. p. 6.

6 GAMERO, Eduardo y FERNÁNDEZ, Severiano, Manual Básico de Derecho Administrativo (14a. ed.). España: Difusora Larousse-Editorial Tecnos, 2018, pp. 66 y 67.

7 ÁVALOS, Eduardo et al., 2014, p. 19.

8 RIZO, Armando, Manual Elemental de Derecho Administrativo, Nicaragua: Ed. Universidad Nacional Autónoma de Nicaragua, 1991, p. 60.

9 GAMERO, Eduardo y FERNÁNDEZ, Severiano, 2018, pp. 63 y 64. 
Dentro de los subconceptos de la discrecionalidad se encuentra la discrecionalidad técnica que se configura cuando la norma requiere de un juicio científico o técnico por parte de la autoridad para la emisión de sus actos lo cual suele ser responsabilidad de organismos públicos especializados.

Sesín considera que el concepto de discrecionalidad técnica debería dividirse en dos partes, por un lado, se tendrían las reglas técnicas que son adoptadas por el ordenamiento y se encuentran reguladas y, por otro, la discrecionalidad que corresponde a la valoración subjetiva y en la posibilidad de elegir dentro de un ámbito jurídico. ${ }^{10}$

La consideración acerca de la inexistencia de la discrecionalidad técnica se basa en que ésta es controlada o controlable por el Poder Judicial en virtud que el contenido técnico le da cierta objetividad a la decisión al demostrar los errores de la administración pública al aplicar algún esquema científico o académico razonable que debe ser susceptible de revisión jurisdiccional aunque en la práctica los tribunales muestran una clara tendencia ha rehusar su intervención en aquellas causas en donde se cuestionan decisiones técnicas de organismos administrativos especializados. ${ }^{11}$

Los Tribunales Colegiados de Circuito prevén una definición acerca de la discrecionalidad técnica en una tesis aislada conforme al siguiente texto: ${ }^{12}$

\section{“DISCRECIONALIDAD TÉCNICA EN MATERIA ADMINISTRATIVA. SU CON- CEPTO.}

La discrecionalidad técnica se define como el arbitrio para valorar o seleccionar, dentro de una pluralidad de opciones, en el contexto de disciplinas distintas al derecho — como la economía, que puede prever varias teorías o técnicas, todas con ventajas o desventajas para alcanzar ciertos objetivos; al igual que tecnologías aplicables en materia de telecomunicaciones - y, de entre ellas, la autoridad puede elegir la mejor o más adecuada, en el entendido de que cualquiera de ellas es igualmente válida, con más o menos límites o niveles de libertad para apreciar."

Según García de Enterría, ${ }^{13}$ el control de la potestad discrecional técnica tiene las siguientes características:

- Su ejercicio requiere un conocimiento técnico especializado que suele estar por encima de los del órgano jurisdiccional.

- El discernimiento de los hechos principales en el ejercicio de la potestad discrecional requiere del uso de dictámenes técnicos expertos como son los periciales para rebatir el criterio utilizado por la Administración Pública.

10 ÁVALOS, Eduardo et al., 2014, p. 20.

11 Ibidem. p. 24

12 Tesis I.1o.A.E.31 A (10ª.), Gaceta del Semanario Judicial de la Federación, Décima Época., t. III libro 16, marzo de 2015, p. 2360. Recuperado de https://sjf.scjn.gob.mx/sjfsist/paginas/DetalleGeneralV2.aspx?Epoc $\mathrm{a}=1 \mathrm{e} 3 \mathrm{e} 1 \mathrm{fdfdf} 8 \mathrm{fcfd} \&$ Apendice $=1000000000000 \&$ Expresion $=$ Discrecionalidad $\% 2520 \mathrm{~T} \% 25 \mathrm{C} 3 \% 25 \mathrm{~A} 9 \mathrm{cnica} \%$ $2520 \mathrm{en} \% 2520$ Materia\%2520Administrativa\&Dominio=Rubro\&TA_TJ=2\&Orden=1\&Clase=DetalleTesisB L\&NumTE $=1 \& E p p=20 \& D e s d e=-100 \& H a s t a=-100 \&$ Index $=0 \&$ InstanciasSeleccionadas $=6,1,2,3,4,5,50,7 \& \mathrm{I}$ $\mathrm{D}=2008769 \&$ Hit $=1 \& \mathrm{IDs}=2008769$ \& tipoTesis $=\&$ Semanario $=0 \&$ tabla $=\&$ Referencia $=\&$ Tema $=$

13

Citado en GAMERO, Eduardo y FERNÁNDEZ, Severiano, 2018, p. 65. 
- Respecto a apreciaciones estrictamente técnicas existe un margen de tolerancia y solo se anula la decisión de la autoridad administrativa cuando haya un error manifiesto.

Conforme al principio de legalidad, la autoridad administrativa se encuentra supeditada a lo que expresamente la ley le permite, esto se conoce como principio de vinculación o vertiente positiva del principio de legalidad por el cual los ciudadanos se encuentran en libertad de realizar todo aquello que no se encuentre prohibido por el ordenamiento legal. ${ }^{14}$

En beneficio del interés general de los ciudadanos es obligación de la Administración Pública el ejercicio de la competencia que le ha sido concedida con el objetivo de que se encuentre disponible al ciudadano, por lo que, la autoridad administrativa debe estar dispuesta a ejercer sus atribuciones. Conforme a una potestad discrecional el órgano administrativo tiene cierta libertad de apreciación sujeta al cumplimiento del fin para el cual fue creado y en beneficio del interés de los gobernados. ${ }^{15}$

Acorde con lo que señala Ávalos, la función de la Administración Pública la llevan a cabo órganos administrativos que tienen la competencia a través de las personas físicas que tienen la titularidad de esos órganos y que realizan la actividad mediante la exteriorización de la voluntad de la institución, por lo tanto, el resultado de la actuación pertenece al órgano competente conforme a las acciones de las personas que deben ser capaces para llevarlas a cabo. ${ }^{16}$

La crítica a la actividad jurisdiccional respecto a sus medios de control del ejercicio de las potestades discrecionales es debido al poder de sustitución del juez respecto de un acto de la autoridad administrativa que entraña la posibilidad de que en virtud de la revisión que realiza de los actos administrativos decida sustituir la opinión administrativa por un criterio propio y, en tal sentido, considerar la posibilidad de que la discrecionalidad reconocida a la Administración Pública pudiera ser indebidamente utilizada por el órgano jurisdiccional más allá de velar por el respeto de la legalidad creando actos administrativos de contenido discrecional en su actividad jurisdiccional. ${ }^{17}$

En este momento es necesario tener claro que las facultades administrativas son las potestades legales concedidas a los funcionarios de la Administración Pública por las cuales pueden realizar los fines de interés general o público y que se encuentran sujetas al principio de legalidad. ${ }^{18}$

Richard F. Elmore señala que la discrecionalidad que inevitablemente se ejerce en cualquier sistema administrativo complejo, deberá ser cuidadosamente limitada, contenida y controlada por un conjunto de mecanismos (de selección,

14 GAMERO, Eduardo y FERNÁNDEZ, Severiano, 2018, pp. 61 y 62.

15 RIZO, Armando, 1991 p. 60.

16 ÁVALOS, Eduardo et al., 2014, p. 75.

17 GAMERO, Eduardo y FERNÁNDEZ, Severiano, 2018, p. 73

18 JIMÉNEZ PEÑA, Sergio, Límites Jurídicos de la Discrecionalidad de las Administraciones Públicas. Recuperado de https://derechoporlavida.com/2015/08/28/limites-juridicos-de-la-discrecionalidad-de-las-administraciones-publicas/ 
supervisión y rutinización) que refuercen la cúspide del sistema en detrimento de la base. ${ }^{19}$

A este respecto, la problemática que se presenta es que el mismo Poder Judicial no cuenta con los elementos o dicho de otra forma cuenta con los mismos elementos y padece las mismas carencias normativas con las que cuenta la autoridad administrativa en este caso el Registro Público del Derecho de Autor del Instituto Nacional del Derecho de Autor, al elegir conceptos de las ramas sujetas de protección de entre los varios que existen, sin contar con un parámetro legal y un procedimiento que defina las etapas que deben seguirse para llevar a cabo el dictamen de las obras literarias y artísticas y, aunque tiene la posibilidad de allegarse de peritos, éstos debieran formar parte del procedimiento administrativo de Registro de Obra, de los que también debería allegarse o contar dentro de su estructura el Registro Público del Derecho de Autor.

Al respecto, la autoridad jurisdiccional tendrá que evaluar si el criterio o definición que decidió utilizar la autoridad registral es correcto y coincide con lo establecido por la norma o al contrario de su interpretación se desprende que no es adecuado o no corresponde su aplicación al caso.

De tal manera que, el funcionario tiene la potestad de decidir, primero, si una creación intelectual corresponde a alguna de las ramas sujetas de protección por el derecho de autor y, segundo, determinar con base en sus criterios que, si bien una creación no corresponde a alguna de las ramas, si equivale a una obra literaria o artística y, por lo tanto, resolver su inscripción incluyéndola por analogía en cualquiera de dichas ramas a su elección. Lo anterior, con la ausencia de conceptos rectores previstos en alguna norma y sin un procedimiento legal para el dictamen de las creaciones intelectuales para, en su caso, ser inscritas en el Registro Público del Derecho de Autor.

Las frases "estará facultada", "podrá", "tendrá permitido" y otras análogas que hacen referencia a la acción de la Administración Pública que aparecen en la normatividad con frecuencia hacen alusión a una potestad discrecional, y cuando aparecen las expresiones "tendrá que", "deberá", etcétera, sugieren la existencia de potestades reguladas, aunque esto no es una regla y depende del análisis en su conjunto para determinarlo. ${ }^{20}$

Con referencia a lo señalado en el párrafo que antecede es conveniente señalar que el artículo 164 fracción I, de la Ley Federal del Derecho de Autor prevé que el Registro Público del Derecho de Autor tiene entre sus obligaciones, inscribir, cuando proceda, las obras y documentos que le sean presentados. A este respecto cabe dilucidar acerca de la frase "cuando proceda", porque implica no inscribir aquello que se encuentra previsto por el propio artículo 164 en su fracción III de la Ley de referencia.

\footnotetext{
19 AGUilar VIllanUeVA, Luis F. et al., La implementación de las políticas, Ed. Miguel Ángel Porrúa. 2003, pp. 251-262.

20 REBOLLO, Manuel (Coord.), Derecho Administrativo. Tomo I: Conceptos fundamentales, fuentes y organización, 3a. ed., México: Difusora Larousse - Editorial Tecnos, 2018, p. 186.
} 
De tal forma que, la autoridad administrativa, en este caso el Registro Público del Derecho de Autor del Instituto Nacional del Derecho de Autor, determina "cuando procede" considerar obras literarias y artísticas susceptibles de inscripción a las creaciones intelectuales que se presentan en el trámite de Solicitud de Registro de Obra.

Cabe precisar que, los actos por los cuales se determina cuáles creaciones intelectuales serán inscritas y en qué forma, así como, cuáles serán objeto de una negativa de registro son consecuencia del ejercicio de una competencia discrecional, distinta de un acto arbitrario en el que se actúa al margen de la ley, es decir es ilegal y, en el caso de la discrecionalidad, se exige que el resultado sea debidamente fundado y motivado.

En el caso del procedimiento que se lleva a cabo en el Registro Público del Derecho de Autor para el dictamen de las creaciones intelectuales, el ejercicio de la competencia es discrecional porque la autoridad se encuentra designada por la Ley Federal del Derecho de Autor, en este caso la autoridad registral dependiente del Instituto Nacional del Derecho de Autor, así también existe la acción que debe realizar dicha autoridad, es decir, el registro o negativa de inscripción; sin embargo, se considera que el mismo ordenamiento legal en materia autoral otorga la posibilidad de que la autoridad en el ejercicio de su competencia realice la evaluación de las creaciones intelectuales para determinar la procedencia del registro conforme a criterios subjetivos y de acuerdo con el procedimiento que considere en libertad de acción.

Es de gran relevancia decir que las resoluciones basadas principalmente en los referidos criterios y evaluaciones de la autoridad registral de la materia de derechos de autor, son la base para la apreciación de otras autoridades para considerar el reconocimiento del derecho de autor respecto de las creaciones inscritas en el Registro Público del Derecho de Autor, por lo que, es de gran trascendencia los conceptos que debe conocer la persona que ejerce las atribuciones registrales para examinar cada una de las creaciones intelectuales que le son presentadas para su inscripción.

Cabe aclarar que, concebir definiciones afines a las ramas reconocidas por el derecho de autor e incorporarlas en la legislación autoral no sería nuevo considerando que la propia Ley Federal del Derecho de Autor en sus artículos 13, 94 y 101 ya prevén algunos conceptos, como los que se presentan a continuación:

- De compilación, integrada por las colecciones de obras, tales como las enciclopedias, las antologías, y de obras u otros elementos como las bases de datos, siempre que dichas colecciones, por su selección o la disposición de su contenido o materias, constituyan una creación intelectual.

- Obras audiovisuales: las expresadas mediante una serie de imágenes asociadas, con o sin sonorización incorporada, que se hacen perceptibles, mediante dispositivos técnicos, produciendo la sensación de movimiento.

- Programa de computación: la expresión original en cualquier forma, lenguaje o código, de un conjunto de instrucciones que, con una secuencia, 
estructura y organización determinada, tiene como propósito que una computadora o dispositivo realice una tarea o función específica.

De tal forma que, así como aparecen las definiciones anteriores bien podría existir en la Ley autoral las definiciones de las demás ramas sujetas de protección y considerar la posibilidad de que una vez plasmadas pueda realizarse una interpretación de éstas y su alcance, en lugar de que cada servidor público o juzgador u otra persona se base solo en los conceptos que considere adecuados o en su propio criterio u opinión para evaluar o dictaminar la creación intelectual de que se trate.

Así mismo, adicional a la falta de definición de las ramas de todas las obras literarias y artísticas reconocidas por el Derecho de Autor, se encuentra el inconveniente de no contar con un perfil descrito en la normatividad para quien realiza la evaluación de las creaciones intelectuales.

En el mismo orden de ideas, se tiene otra limitante para lograr que la evaluación de las creaciones intelectuales que se presentan para su inscripción en el Registro Público del Derecho de Autor, se trata de la inexistencia de un procedimiento legal que considere las etapas para llevar a cabo el dictamen de obras que incluya aspectos como: la revisión del contenido, la confrontación con los conceptos de lo que no es objeto de protección por el derecho de autor y para considerar las características o la falta de ellas para llevar a cabo la negativa de inscripción.

Las obras literarias y artísticas son producto de la labor de los autores y se constituye como la materia prima para el uso y explotación que realizan las industrias creativas o culturale ${ }^{21} \mathrm{u}$ otros mecanismos de aprovechamiento, la falta de un adecuado dictamen de obras literarias y artísticas limitan el incentivo a la actividad creativa de los autores al no contar con la certeza de que su creación es evaluada bajo estándares homogéneos de dictamen especializado y en su lugar se evalúan conforme al ejercicio de competencias discrecionales para resolver la procedencia o improcedencia de la inscripción de las creaciones intelectuales.

De lo anterior se considera que se debe implementar una política pública que incentive la protección del derecho de los creadores, incluyendo reformar la Ley Federal del Derecho de Autor, para complementar su artículo 13 con el objetivo de incluir conceptos afines de cada una de las ramas sujetas de protección por el Derecho de Autor, reformar el Reglamento de la Ley Federal del Derecho de Autor, para complementar lo dispuesto por el artículo 164 fracción I de la Ley autoral y establecer el procedimiento para llevar a cabo el dictamen de las creaciones intelectuales con fines de determinar la procedencia de inscripción de obras

21 Tomando como referencia el marco de estadísticas culturales de la Organización de las Naciones Unidas para la Educación, la Ciencia y la Cultura (UNESCO) 2009, ésta propuso una definición amplia para industrias culturales y las industrias creativas como: "Aquellos sectores de actividad organizada que tienen como objeto principal la producción o la reproducción, la promoción, la difusión y/o la comercialización de bienes, servicios y actividades de contenido cultural, artístico o patrimonial." Recuperado de http://www.unesco.org/new/es/ culture/themes/cultural-diversity/diversity-of-\%09cultural-expressions/tools/policy-guide/como-usar-esta-guia/ sobre-definiciones-\%09que-se-entiende-por-industrias-culturales-y-creativas/ 
literarias y artísticas en el Registro Público del Derecho de Autor y adecuar el Reglamento Interior del Instituto Nacional del Derecho de Autor y los manuales administrativos de organización y de procedimientos, para integrar a su estructura peritos con el perfil de especialistas en obras literarias y artísticas que realicen el dictamen de procedencia del registro.

Para implementar estos cambios debe considerarse la influencia que pueden llegar a tener las personas que se encuentran en las primeras etapas del procedimiento de registro de obra, como son las etapas de información al público y de recepción de documentos en ventanilla, en virtud que en ambas etapas, el ciudadano es muy susceptible de someterse a la opinión, recomendación o indicación de las personas de base o de apoyo en el módulo de información y estar prevenidos ante situaciones como las que señala Lipsky ${ }^{22}$ los empleados de base disfrutan de discrecionalidad porque las definiciones de sus puestos de trabajo suponen una sensibilidad y un juicio razonable y promueve su autoestima e induce a los ciudadanos a creer que estos trabajadores son quienes tienen la llave de su bienestar.

Considera Lipsky que en teoría se puede pensar que muchas de las situaciones adversas que se presentan podrían desaparecer si se eliminara la discrecionalidad de los empleados, pero no es así porque señala que ciertas características de la labor que desempeñan estos empleados de base no permiten reducir drásticamente su forma de actuar y sustituir la forma en que hacen sus tareas llevándolas al terreno complejo mediante el uso de reglas, guías o instrucciones. ${ }^{23}$

Lipsky distingue dos características asociadas al papel que tienen los empleados de base en la elaboración de políticas públicas en su lugar de trabajo, por un lado, niveles relativamente altos de discrecionalidad y cierta autonomía respecto a la autoridad organizativa, a diferencia de lo que sucede con otros funcionarios, lo cual no significa que los empleados de base no estén sujetos a la normatividad, sin embargo, en el caso en estudio la inexistencia de definiciones formales de las ramas sujetas de protección por el derecho de autor, así como lineamientos claros respecto al dictamen de obras y un procedimiento para realizarlo, hacen susceptible que los empleados usen las alternativas que tienen a la mano con base a experiencia o paradigmas propios.

De tal forma que no cabe duda que en la implementación tanto de las medidas para el mejoramiento del procedimiento de registro de obra, que va desde la reforma de ley que incluya las definiciones de las ramas sujetas de protección por el derecho de autor, las adecuaciones reglamentarias y los ajustes necesarios a los manuales de organización y de procedimientos del Instituto Nacional del Derecho de Autor, deben estar ligados a una política pública que incluya en su planeación e implementación a los sectores involucrados.

\footnotetext{
22 LIPSKY, Michael, Los Empleados de Base en la Elaboración de Politicas Públicas. Incluido en Lecturas de Gestión Pública, Editor: Ministerio de Administraciones Públicas. Instituto Nacional de Administración Pú23 blica y Ministerio de la Presidencia, Boletín Oficial del Estado, Madrid, 1996, pp. 281-293.

Ibidem.
} 
Al respecto como señala Richard F. Elmore, las políticas serían mejores si quienes las elaboran pensaran en la factibilidad de su implementación antes de establecer los procedimientos a seguir. ${ }^{24}$

Los derechos de autor han sido estudiados desde diversas perspectivas, y esta vez ha sido una gran oportunidad para dedicarle tiempo a la investigación y análisis de las actividades vinculadas con el Procedimiento de Registro de Obras en el Registro Público del Derecho de Autor del Instituto Nacional del Derecho de Autor tendientes a la evaluación o dictamen de las creaciones intelectuales presentadas con fines de inscripción para ser consideradas obras literarias y artísticas sujetas de reconocimiento por el derecho de autor.

El derecho de autor se conforma por los privilegios de carácter personal y patrimonial reconocidos a los autores respecto de sus obras literarias y artísticas y la relación con los sujetos que usan y explotan sus creaciones y los que los representan.

En virtud de la importancia de la protección del Derecho de Autor es trascendente contar con un Registro Público autoral dotado de los elementos y herramientas suficientes para emitir resoluciones que brinden seguridad jurídica basadas en conceptos legales de las ramas sujetas de protección por el derecho de autor, a través de un procedimiento debidamente regulado que determine los requisitos mínimos para llevar a cabo la evaluación de las creaciones intelectuales que se presentan para su registro, seguido por peritos o expertos en el dictamen de creaciones intelectuales.

Es indudable que disminuir el ejercicio de la competencia discrecional es un factor para reducir la incidencia de actos que pudieran ser considerados contrarios a la ley, no solo en el Registro Público del Derecho de Autor sino en la Administración Pública además de que permite incorporar las condiciones para brindar confianza legítima en favor de los gobernados, un concepto que aún no logra tomar las dimensiones de estudio para su adopción en México y en Latino América.

Conforme a la investigación y análisis realizados en consideración al sistema de indagación, se demostró el ejercicio de competencia discrecional en el Procedimiento de Registro de Obra. La autoridad tiene libertad de apreciación en el ejercicio de sus potestades mediante la valoración subjetiva de las obras y los funcionarios no están por encima de la ley, sino a partir de ella, actúan de forma discrecional para el cumplimiento de su facultad.

Así, para contar con un procedimiento de registro de obras literarias y artísticas sin ejercicio de competencia discrecional se considera la implementación de una política pública de protección del derecho de autor que incluya diversas reformas legales y administrativas con la debida planeación e implementación para el logro de exitoso de los objetivos.

\section{BIBLIOGRAFÍA.}

AGUILAR VILLANUEVA, Luis F. et al., La implementación de las políticas, Ed. Miguel Ángel Porrúa. 2003.

$\overline{24}$ AGUilar VILlanUEVA, Luis F. et al., p. 251. 
ÁVALOS, Eduardo et al., Derecho administrativo 1, España: Alveroni Ediciones, 2014.

BORGES, Jorge Luis y ARIAS, Grethel, Discrecionalidad y legalidad. Cuba: El Cid Editor | apuntes. 2009.

GAMERO, Eduardo y FERNÁNDEZ, Severiano, Manual Básico de Derecho Administrativo (14a. ed.). España: Difusora Larousse - Editorial Tecnos. 2018.

JIMÉNEZ PEÑA, Sergio, Límites Jurídicos de la Discrecionalidad de las Administraciones Públicas. Recuperado de https://derechoporlavida.com/2015/08/28/ limites-juridicos-de-la-discrecionalidad-de-las-administraciones-publicas/.

REBOLLO, Manuel (Coord.), Derecho Administrativo. Tomo I: Conceptos fundamentales, fuentes y organización, 3a. ed., México: Difusora Larousse - Editorial Tecnos, 2018.

RÍOS, Lautaro, Los poderes discrecionales, citada de su obra Derecho administrativo y seguridad jurídica, en Revista de Administración Pública, núm. 099. España: Centro de Estudios Políticos y Constitucionales (CEPC), 1982.

RIZO, Armando, Manual Elemental de Derecho Administrativo, Nicaragua: Ed. Universidad Nacional Autónoma de Nicaragua, 1991.

Tesis I.1o.A.E.31 A $\left(10^{\mathrm{a}}\right.$.), Gaceta del Semanario Judicial de la Federación, Décima Época., t. III libro 16, marzo de 2015, p. 2360. Recuperado de https:// sjf.scjn.gob.mx/sjfsist/paginas/DetalleGeneralV2.aspx?Epoca $=1 \mathrm{e} 3 \mathrm{e} 1 \mathrm{fdfdf} 8$ fcfd\&Apendice $=1000000000000 \&$ Expresion $=$ Discrecionalidad $\% 2520 \mathrm{~T} \%$ 25C3\%25A9cnica\%2520 en\%2520Materia\%2520Administrativa\&Dominio $=$ Rubro\&TA_TJ $=2 \&$ Orden $=1 \&$ Clase $=$ DetalleTesisBL $\&$ NumTE $=1 \& E p p=20$ $\&$ Desde $=-100$ \&Hasta $=-100 \&$ Index $=0 \&$ InstanciasSeleccionadas $=6,1,2,3,4,5$, $50,7 \& \mathrm{ID}=2008769 \& \mathrm{Hit}=1 \& \mathrm{IDs}=2008769 \&$ tipoTesis $=\&$ Semanario $=0 \&$ tabla $=\&$ Referencia $=\&$ Tema $=$ 